\title{
AS CICATRIZES DE VIOLETA, UMA HEROÍNA ÀS AVESSAS
}

\section{ALLEID RIBEIRO MACHADO}

Universidade de São Paulo alleid@usp.br

RESUMO: Violeta é a protagonista de Os meus sentimentos, romance escrito pela autora portuguesa Dulce Maria Cardoso, publicado em 2005. Esse artigo interessa-se especialmente em sondar a construção dessa personagem, por se tratar de uma mulher totalmente fora dos padrões de beleza socialmente estabelecidos como ideais, carente de estima própria e que, no limite da vida e da morte, encontra-se cindida entre o amor e o desejo de vingança, entre a dor e o desejo de evasão. Além de encontramos na narrativa material e substância para elucidarmos importantes questões de gênero e corporalidade, o artigo procura ressaltar ainda uma importante discussão de cunho ideológico que atravessa o romance. Em Os meus sentimentos é possível entrevermos, mesmo que sorrateiramente, certa desilusão com a revolução portuguesa dos anos 70, algo que mais tarde será amplamente destrinçado em $O$ retorno, de 2011.

PALAVRAS-CHAVE: Literatura de autoria feminina; corporalidade; gênero; modernidade tardia; estudos culturais 


\section{VIOLETA'S SCARS, AN HEROIN INSIDE OUT}

ABSTRACT: Violeta is the protagonist of Os meus sentimentos a novel by the Portuguese writer Dulce Maria Cardoso, published in 2005. This article explores this character construction because she falls out of the socially accepted ideal beauty canons for women, she lacks self-steem and in the limits between life and death she is torn between love and vindictiveness, pain and desire for escape. Apart from offering material to elucidate relevant gender and corporality questions, an important ideological question is studied. In Os meus sentimentos it is possible to glimpse, although covertly, some disillusionment with the Portuguese revolution in the seventies, something that will be openly shown in O retorno in 2011.

KEY WORDS: Women writer's literature, corporality, gender, late modernity, cultural studies as primeiras linhas de Reflexóes sobre o exílio, Edward Said aponta-nos quão maçadora é a lembrança provocada pelo exílio. Ao discorrer acerca desse local inapropriado, desconfortável e incomum, o autor procura ressaltar que, talvez, o pior não seja a simples e tangível rememoração de fatos para sempre subjugados a uma condição relativamente impossível de ser revertida, e sim a revitalização, pelos laços da memória, da assustadora condição da vivência, ou da terrível experiência que o exílio provoca.

Para Said, eminentemente associada à experiência do degredo está a condição dolorosa e fatídica de se estar e se sentir "fora do lugar", vivenciada pelo sujeito deslocado de sua terra natal - seu berço, sua casa:

E, embora seja verdade que a literatura e a história contêm episódios heroicos, românticos, gloriosos e até triunfais da vida do exilado, eles não são mais do que esforços para superar a dor mutiladora da separação. As realizações do exílio são permanentemente minadas pela perda de algo deixado para trás para sempre (Said, 2003: 46).
Se alguma literatura agiu no sentido de idealizar essa desafortunada experiência, pelo menos do ponto de vista de Said, uma leitura de Os meus sentimentos (2005), de Dulce Maria Cardoso, revelar-nos-ia um contraponto interessante, ao analisar-se a experiência de exílio provada pela personagem Violeta. Isso poderia ocorrer uma vez que a própria narrativa permite-nos observar, em suas entrelinhas, a construção de uma mulher exilada não de sua nação, de cujas fronteiras jamais saiu: "nunca fui para longe de mais" (Cardoso, 2005: 89), entretanto, metaforicamente, de uma suposta identidade.

Galardoado em 2005 com o Prêmio da União Europeia para a Literatura, vemos desenrolar-se em Os meus sentimentos a história de Violeta, uma mulher que, após sofrer um acidente de carro e cuja vida está por um fio, começa a rememorar o que tem sido a sua existência, de qualquer forma revelando o que ela tem sido: uma mulher completamente "inadequada" quer para os padrões de beleza, quer para os paradigmas de comportamento, considerados e elegidos como ideais pela sociedade de seu tempo.

Em meio a uma narrativa que, do ponto de vista estrutural, aproxima-se da oralidade, seja pela indicação de pensamentos fluidos que insinuam flashes de memória, ou mesmo pelo uso de vocábulos e estruturas sintáticas altamente polissêmicas, em Os meus sentimentos o leitor é levado a partilhar os anseios de uma personagem que, ao longo da narrativa, vai abrindo e revelando as páginas de sua vida. Daí a explicação para um título tão intimista, claramente declarado pelo uso no plural do pronome possessivo "meus", antecedido pelo artigo definido "os", depois seguido do substantivo "sentimentos". Sem dúvida alguma, Os meus sentimentos é, antes de tudo, um livro de confidencialidades, a revelar-nos os sentimentos "de Violeta", uma heroína às avessas.

Em torno do título, notamos que "os meus sentimentos" nos remete a uma expressão dita em ocasiões fúnebres, para anunciar condolências pela morte de alguém. Assim, uma leitura mais profunda em torno dele levar-nos-ia à possibilidade de interpretá-lo por um viés mais polissêmico, conforme sugerido pela teoria dos atos da fala. 
Para Searle (1979), todo enunciado contém em si um aspecto imediatamente comunicável, que ele nomeia como ato proposicional, e outro, por sua vez, implicitamente colocado, chamado de ilocucional. Ao dizermos "os meus sentimentos" em uma situação fúnebre, estamos convencionalmente repetindo uma expressão exclusivamente utilizada nestas ocasiões, a fim de sermos educados. Além disso, atrelada a essa expressão, está a necessidade de "demonstramos" que somos sensíveis, que temos compaixão, que somos capazes de compartilhar a dor do próximo. A narrativa de Dulce Maria Cardoso parece flertar com os conteúdos polissêmicos dos enunciados. Vejamos como exemplo a rememoração de Violeta acerca da morte de sua mãe, D. Celeste:

a compaixão é a única coisa que podemos oferecer aos outros; os meus sentimentos; obrigada, muito obrigada, um aperto de mão, um abraço, um beijo rápido na face, depende das pessoas, da intimidade, da circunstância do cumprimento, os gestos ainda reservam algumas surpresas ao contrário das palavras que se repetem numa lengalenga, as minhas condolências, ainda era muito nova, os meus pêsames, vamos sentir a falta dela, não merecia ir tão cedo, coitadinha (Cardoso, 2005: 259)

Permeado por uma fina camada de ironia, principalmente quando expressa a falível condição humana: "dai-nos o sofrimento alheio e livrai-nos do nosso, amém” (Cardoso, 2005: 259), o discurso de Violeta evidencia um desgosto pertinente às relações humanas que, engendradas por palavras que se tornaram vazias, não passam de maçadoras "lengalengas" (Cardoso, 2005: 47). Em última instância, a expressão que intitula o livro também está implicada ao próprio desejo de evasão sonhado por Violeta. Ao rememorar uma vida de que, na verdade, deveria sentir "vergonha": "é sempre de nós que temos vergonha, nunca dos outros” (Cardoso, 2005: 296), a protagonista sonha com um futuro desligado de uma realidade que lhe é insuportável. Nesse sentido, "os meus sentimentos" é uma evocação subliminar, ao mesmo que também é um anúncio, do desejo de morte, ao menos física, da protagonista.

A história inicia-se com um acidente inesperado sofrido por Violeta, numa noite de chuva torrencial, ou, mais especificamente, com a lembrança atordoada da personagem "não devia ter saído de casa, não devia ter saído de casa" (Cardoso, 2005: 9). Violeta decide viajar no mesmo dia em que, enfim, consegue vender a casa dos pais, local a todo tempo lembrado como um fardo ruim. Conhecemos nas páginas de $O s$ meus sentimentos a história de uma mulher que jamais se sentiu amada por seus progenitores, Celeste e Baltazar. O desejo de vender a todo custo a casa onde precisou viver até a vida adulta "estou satisfeita, vendi a casa, nunca mais lhe pertenço, finalmente livre" (Cardoso: 2005: 24), reflete o desgosto que tem por um espaço que, via de regra, concentra a memória de um passado envolto em más recordações, configurado, por exemplo, no desconjuntado relacionamento entre seus pais.

Os saltos finos de minha mãe de um lado para o outro no quarto, a pararem bruscamente na borda da cama, ao lado de meu pai, este país não nos merece o cabelo penteado de minha mãe muito perto do rosto de meu pai, o colar de pérolas quase a tocar no ombro dele, escuta-me Baltazar, mas o meu pai já estava longe, já se tinha exilado no hábito de ficar horas no quintal a olhar para os pássaros, o teu pai não está maluco (Cardoso, 2005: 102).

Tal qual uma forma literária em evolução, como considerou Bakhtin (1988), e na esteira do conceito de contemporaneidade "líquida" e "disforme", conforme nos orienta Bauman (2001: 9), ao referir-se a esses dois conceitos como "metáforas adequadas quando queremos captar a natureza da presente fase, nova de muitas maneiras, na história da modernidade", o gênero romanesco em Dulce Maria Cardoso faz-se por meio do inacabamento dos sentidos. Além disso, por baixo do plano mais imediato de interpretação dos discursos que formam o tecido ficcional, há camadas mais profundas de significação, que se abrem, por exemplo, para o âmbito ideológico-político português. Nesse sentido, há na narrativa algumas referências à popularmente conhecida Revolução dos Cravos, ao trazer à tona uma reflexão relacionada ao passado nacional, localizado, mais precisamente, no período ditatorial dos anos 70. Não é demais lembrar que a ficção contemporânea por- 
tuguesa tem se voltado para esse aspecto importante da vida política de Portugal. No entanto, no caso específico de Os meus sentimentos, a revolução é rememorada não exatamente como momento glorioso da democracia, mas antes pela violência de seus rastros. Conforme lembra-nos Margarida Calafate Ribeiro, esse tipo de ficção, na qual se enquadraria também a narrativa de Dulce Maria Cardoso, é formada pelo contra-discurso, de modo que "o império e sua herança" podem ser lembrados "tanto com memórias douradas [...] como com memórias cinzentas da brutalidade do colonialismo e da Guerra Colonial que pôs fim ao império" (2012: 90).Em Os meus sentimentos, as memórias em torno do 25 de abril revelam-se neste segundo aspecto referido por Calafate. São memórias cinzentas, principalmente metaforizadas na casa de seus pais. A casa da infância, que poderia ser lembrada como espaço de aconchego, serenidade e paz, é, antes, rememorada, reversamente, como espaço de más recordações, de desprezo, de violência. Da mesma maneira o rescaldo revolucionário é lembrado como uma experiência traumática da metamorfose da vida nacional portuguesa.

O espaço da casa reserva-se, desse modo, como local depreciativo, pois era a habitação dos pais, Baltazar e Celeste, pelos quais Violeta guarda ressentimentos e mágoas. Em relação a eles, sabemos que Baltazar fora "um daqueles importantes que foi preso [...] um inimigo da revolução" (Cardoso, 2005: 25, 105), tornando-se depois um ser alienado, que nutria o hábito de matar passarinhos: "um dos pássaros que o meu pai perseguia na gaiola, anda cá bichinho, um dos pássaros que foi preso nos dedos em tenaz, um leve estalido e o pássaro sem outro céu para além da mão onde jazia" (Cardoso, 2005: 38). Um ser que "escolheu para se exilar um quintal cheio de gaiolas, um hábito, os hábitos são difíceis de desentranhar, o meu pai que nunca chegou a perceber como gostava do país, nem como o país precisava dele" (Cardoso, 2005: 85); já Celeste, a mãe, para quem em qualquer circunstância importava ser "chic, très chic" (Cardoso, 2005: 19), é uma mulher de família supostamente abastada, que vive de aparências, que despreza tudo o que não condiz com o espaço urbano, como por exemplo, a casa de seus sogros. visitávamos duas vezes por ano os campónios que ficavam muito agradecidos, uns velhos ignorantes que nem sabiam o que era o joie de vivre que a nora, uma santa que salvou o filho tanto falava [...]

os campónios estendiam as mãos sôfregas para nos agarrar, a minha mãe libertava-se e ia para o quarto onde se recompunha da viagem, a única divisão daquela casa que, por exigência dela, tinha algum conforto, sentava-se no banquinho de boudoir, nem na casa dos campónios perdia o hábito de meia dúzia de palavras na língua mais bonita do mundo [...]

a minha mãe demorava-se no quarto, não queria sentar-se à mesa, comer o que os campónios tinham preparado, demorava-se, o meu pai chamava-a, um grito impaciente, estamos todos à tua espera, Celeste, e a minha mãe saía do quarto com um sorriso que parecia autêntico (Cardoso, 2005: 211).

A transcrição da cena de visita dos pais de Violeta aos avós paternos sugere-nos, numa primeira leitura, a superficialidade de Celeste, sempre preocupada em manter uma aparência elegante e refinada, que nada mais é do que fruto da educação citadina, que despreza tudo o que se relaciona ao campo, à aldeia. Para ela, apenas Paris importava, por representar um verdadeiro paradigma de civilização. A casa dos pais de Violeta, ou o espaço em que habitam os avós, são uma pequena amostra de um espaço geográfico que, assim como a nação, perdeu o seu sentido original. Numa leitura menos rasa, observamos que nem mesmo Portugal importava a Celeste, à medida que não lhe representava um país forte e soberano, o império colonial de outrora, após a revolução engendrada por uma "cambada de oportunistas" (Cardoso, 2005: 104).

Portugal era como a casa dos campônios; já a casa de Celeste e Baltazar, apenas a tentativa de fazer dela um lugar melhor: como a França, modelo de nação que Celeste esforçava-se por fazer valer, quer no uso do idioma, nos costumes da casa, ou na lembrança "minha mãe fechava as portadas da sala e pensava em Paris, na única vez que tinha ido a Paris, já que o meu pai não viu nada de especial em Paris e nunca mais quis lá voltar” (Cardoso, 2005: 106).

UNED. REI, 2 (2014), pp. 171-186

ISSN 2340-9029 
Segundo nos adverte Paiva (2010:2), a representação literária portuguesa contemporânea tem procurado refratar a fatídica experiência revolucionária, conjugada, de um lado, pelo desgaste de um regime que cegamente sustentou por mais de uma década em várias frentes africanas uma guerra sem esperanças e de duvidosa justiça, e, por outro, pelo delineamento de um novo regime à procura dos caminhos da democracia. As memórias de Violeta em torno da casa como espaço de rejeição, revelam-nos não apenas o desejo de evasão de Celeste ou a alienação de Baltazar em torno de um país não mais representativamente imperial e poderoso. Antes, demonstram a alienação de um povo que, em meio a uma revolução que se mostrava libertária e a um processo de descolonização, insistia em mostrar-se insatisfeito com a ideia de voltar a ser apenas mais um país na Europa, não mais entendido como centro ou "nação colonizadora por excelência" (Lourenço, 1984: 26).

Dessa forma, como o romance aponta para certa abertura à relativização da verdade: "a verdade depende do ponto de vista" (Cardoso, 2005: 104), notamos que, no plano ideológico, há no romance uma tênue crítica no que se refere aos efeitos diretos da Revolução dos Cravos na vida cotidiana, pois Violeta, como um sujeito representativo do individualismo da modernidade tardia, alienado de suas potencialidades, também irá relativizar os efeitos posteriores à conflagração. Portanto, a seu ver, mais uma vez, reversamente, para longe de qualquer mudança efetiva política ou social levada a efeito pela ou por qualquer insurreição, está a natureza humana e sua falível condição, imutável em sua essência.

Quaisquer que sejam os efeitos da resistência armada pela revolução, todo o esforço viu-se diluído quando, na contemporaneidade, cada sujeito não pode levar adiante os seus projetos libertadores em meio a um sistema que, sustentado pela aura da redemocratização, por sua onipotência, anulou qualquer força de resistência. Não é por outra razão que Violeta não crê nos esforços da coletividade, colocando em xeque se tais diligências realmente terão valido a pena. A pergunta que lhe parece perturbar a razão é: o que sobrou desse passado? "Não falo de política, falo de natureza que para o bem e para o mal não há revolução que mude" (Cardoso, 2005: 106). Ressaltemos que tal desilusão com a revolução e os seus efeitos será um tema amplamente abordado em outro livro de Dulce Maria Cardoso: O retorno, de 2011. Esse romance, que, a nosso ver, fecha uma temática que fora, paulatinamente, sendo trabalhada pela autora, desde a publicação de Campo de sangue, tem como principal mote a lembrança da guerra colonial, tingida pelo sangue derramado em África. Assim, sob o contexto do 25 de abril, n'O retorno, conhecemos a desconfortável experiência de exílio vivenciada por Rui, um adolescente retornado, obrigado a abandonar Luanda e partir com sua família, sem esperança de dias melhores, para a metrópole.

Para além dessas questões ideológico-políticas, em Os meus sentimentos somos envolvidos numa atmosfera marcada pela sensação de desconforto que, de certa forma, atravessará toda a narrativa: "a posição em que me encontro, de cabeça para baixo, suspensa pelo cinto de segurança, não me incomoda, o meu corpo, estranhamente, não me pesa, o embate deve ter sido violento" (Cardoso, 2005: 9). É válido sublinhar que, se de um lado, como observamos, a protagonista é marcada por um processo de descontentamento espacial, gerado pela lembrança da casa onde viveu, de outro lado, ela será marcada pela angústia do não pertencimento, ou, em outras palavras, por um autoexílio identitário.

Deslocada de uma identidade socialmente estabelecida como ideal, a narradora-personagem é o reflexo de um sujeito fora do lugar. Essa sensação, sobretudo existencial, partilhada no seio de uma sociedade, como ressalta Eduardo Lourenço (1999), ambiguamente marcada pela nostalgia saudosa e pela melancolia, é atravessada pelo sentimento de incerteza correlacionado a um tempo líquido, disforme, incerto, muito pertinente a uma época histórica: à vulgo pós-modernidade.

Não é por outra razão que em Os meus sentimentos a verdade nunca é revelada totalmente "a verdade depende do ponto de vista" (Cardoso, 2005: 104), sendo apenas sugerida, "está sempre entre nós 
e os outros, não pertence a ninguém" (Cardoso, 2005: 105). Partilhamos, assim, versões organizadas pelos fios da memória de Violeta, de modo que, ao chegarmos ao próximo parágrafo, não temos certeza de nada. Aí está umas das faces mais interessantes de Dulce Maria Cardoso. Habilmente a autora instaura a ambiguidade como traço marcante da narrativa, aliada à ideia de incerteza. Nesse sentido, é válido lembrar que Os meus sentimentos refrata certos traços social e culturalmente presentes em nossa contemporaneidade. O mal estar vivenciado por Violeta e a própria condição de incerteza a que somos expostos, representam, em última instância, a "pós-modernidade", período que, conforme Terry Eagleton (1998) tomaria corpo como representação de uma fase adiantada do capitalismo global, tardio.

Em consonância a um dos desejos engendrados pelo romance português contemporâneo, que é o de retratar o mundo caótico e instável por uma perspectiva subjetiva e individualista, o romance de Dulce Maria Cardoso faz-se, sobretudo, pela fragmentação do enredo que, engendrado num foco narrativo em primeira pessoa, permite-nos ir acompanhando a condução da narrativa sob a perspectiva do discurso de uma mulher que, em todo o caso, não está em estado sóbrio, quer porque acabara de sofrer um acidente, quer porque temos a informação de que conduzia possivelmente embriagada: "sempre vais viajar esta noite [...] não devias beber tanto" (Cardoso, 2005: 84).

Dessa forma, o texto ficcional de Dulce Maria Cardoso instaura e partilha com os seus leitores a ideia da desconfiança da verdade, porque em Os meus sentimentos somos afrontados pela ideia de que a verdade é uma versão elaborada sob a óptica de quem a conta. Uma verdade é a versão contada, outra é a verdade vivenciada, ainda outras são as versões contrárias, reversas, que os que conviveram com Violeta contam segundo a rememorização dela. O jogo da verdade entra em cena como uma possibilidade de despertar desconfiança, desconforto, de modo que tanto a narradora-personagem quanto nós, leitores, ficamos imersos no campo da indeterminação.

É válido ressaltar que a narrativa evidencia ainda uma fina camada crítica em torno de gênero e corporalidade. Já nas páginas iniciais do livro, sabemos que Violeta está inconsciente, mas apenas suspeitamos que esteja morta. De qualquer maneira, a única certeza é que desde as primeiras linhas imediatamente adentramos a sua memória agonizante, em que se vai passando, multifacetada e disformemente, as cenas da vida que viveu, que se habituou a viver e que, por muitas razões, a levou até o momento do acidente. De qualquer forma, observarmos, no desenrolar da narrativa, as feridas pessoais e as desilusões de uma mulher possivelmente frustrada. Há em torno de Violeta uma atmosfera de isolamento que resulta na visualização da imagem de um sujeito "inadequado", tanto para os padrões de beleza socialmente estabelecidos como ideais: "sou tão ridícula com os sapatos de salto alto e a saia justa"; "[...] no meu corpo, se aperto aqui arrepanha dali" (Cardoso, 2005: 39, 198); como no que tange aos modelos de comportamento esperados para o gênero feminino "uma mulher das mais ordinárias"; "[...] conheço de cor o meu aspecto de puta barata” (Cardoso, 2005: 65, 139).

O sentimento de inadequação em Os meus sentimentos, no que se relaciona à construção da personagem protagonista, que, aliás, está longe de ser um modelo idealizado do feminino, abrange, assim, tanto a esfera corporal quanto a comportamental; e projeta-se na rejeição que sente pela sociedade, que a vê como uma mulher promíscua e esteticamente out: "olha aquela gorda perdida de bêbada" (Cardoso, 2005: 12). O mesmo sentimento pode ser alargado para a sua própria família, ou seja, para os seus pais: "está miúda é impossível"; "está miúda só diz disparates" (Cardoso, 2005: 160, 209); assim como para sua filha, Dora: "esta noite no restaurante a minha criança repreendeu-me, tem vergonha de mim" (Cardoso, 2005: 37).

Não é por outra razão que, na fronteira da vida e da morte, Violeta acredita que a libertação das frustrações que marcaram os seus dias deve existir num outro plano, numa outra vida, em que poderá flanar levemente, desligada de todo o peso (inclusive corporal) que fora a sua vida terrestre. Esse anseio reflete a inabilidade de lidar 
com a frustração de "não ter sido o que esperavam dela"; e representa a única possibilidade, talvez, de descanso, como também de completude, na busca por um amor possível:

desde sempre, em todo o lado, a qualquer hora, um entendimento, ele está à minha espera na estalagem sobre o mar, avanço, não tenho medo de nada, nem sequer do amor, os meus olhos rasos de felicidade, na minha pele as cicatrizes de todos os meus sonhos, a partir de hoje nada vai ser diferente, à minha frente um mar de tempo sempre igual, a minha canção a tocar eternamente (Cardoso, 2005: 304-305).

"Eu creio que a senhora sonha talvez demais [...]. Digo-lhe que faz mal, que é melhor, muito melhor contentar-se com a realidade; se ela não é brilhante como os sonhos, tem pelo menos a vantagem de existir", diria a empregada inglesa, Mrs. Oswald, em A mão e a luva, de Machado de Assis, nos finais do século XIX. Contudo, se o desejo de evasão de Violeta soaria muito mal aos ouvidos de um realista como Machado de Assis, no século XXI, esse desejo parece familiar para aqueles que ocupam o espaço do desprezo, do afamado bullying.

Violeta é uma mulher que tem na bebida e no sexo desenfreado os escapes para as suas frustrações. Para ela não existem relacionamentos efetivamente duradouros, por isso, nesse âmbito, notamos certo ceticismo em seu discurso: "conheço o amor de ouvir falar" (Cardoso, 2005: 41). A protagonista jamais acreditou na possibilidade de uma união pautada em sentimentos recíprocos: "ainda não deixei de me espantar com os que não conseguem comer ou dormir sozinhos, com os que se queixam da solidão, talvez sejam felizes os que conseguem suportar os outros" (Cardoso, 2005: 22). Os relacionamentos furtivos de Violeta são uma espécie de dom juanismo apressado, vazio, terminados logo após a conquista.

estacionada no parque para camionistas, com os máximos acesos, aguardando a minha presa desta noite, o camionista mais curioso, mais inquieto, uma vez identificada a presa ajo segundo as regras que a minha experiência neste tipo de caça me permitiu construir, sou sempre cautelosa, e numa noite destas não me convém espantar a presa, os homens são os animais mais medrosos que conheço, a minha primeira regra consiste numa troca de papéis, torno-me a presa perfeita de qualquer caçador, mesmo do mais inexperiente, quando tiver saciado a carne não me incomoda que descubram a verdade, até me divirto quando isso acontece (Cardoso, 2005: 29)

O uso do corpo não parece condizer com uma conquista efetiva da liberdade feminina em torno do prazer. Na verdade, o que se nota é o uso negativo e exacerbado do direito de fazer uso de sua sexualidade, de relacionar-se com o outro, ou mesmo com o próprio corpo. O sexo e o prazer realizam-se como um risco a correr-se, ou mais propriamente como um ato de violência contra o desprezo estúpido dos pais, ou dos rapazes com os quais mal se relacionou na juventude "os rapazes gostavam de mim nas matinês [...] quando as luzes do cinema se apagavam os rapazes vinham ter comigo" (Cardoso, 2005: 41, 43). Esse comportamento acompanha Violeta desde a sua adolescência, quando se fazia presa fácil para os garotos.

As lembranças de Violeta são a tradução de suas frustrações e estão intimamente ligadas ao passado, recuperado pelo próprio trabalho da memória. Tal rememoração faz-se em meio à narrativa, de forma fragmentada, resultando num romance propositalmente desestruturado. A historiadora Ecléa Bosi em Memória \& sociedade: lembrança de velhos, livro que trata da memória social, ancorado na velhice, afirma que "na maior parte das vezes, lembrar não é reviver, mas refazer, reconstruir, repensar, com imagens e ideias de hoje, as experiências do passado" (2009: 55). Violeta faz sua rememoração, já a certa altura de sua vida. Ela volta ao passado "refazendo-o" à luz do presente, pois:

a lembrança é uma imagem construída pelos materiais que estão, agora, à nossa disposição, no conjunto de representações que povoam nossa consciência atual. Por mais nítida que pareça a lembrança de um fato antigo, ela não é a mesma imagem que experimentamos na infância, porque nós 
não somos os mesmos de então e porque nossa percepção alterou-se e, com ela, nossas ideias, nossos juízos de realidade e de valor. (Bosi, 2009: 55)

No fim das contas, a narrativa traz à superfície a imagem de uma mulher talhada pela frustração e pelo desamor, que decidiu viajar, inapropriadamente, numa noite de temporal, a fim de levar as ceras depilatórias que prometera às suas clientes: "viajo na noite do temporal" (Cardoso, 2005: 11). Como consequência, acabou por ser "vítima" de um acidente de automóvel, ficando a dúvida, nas entrelinhas da história, se, de fato, ela fora vítima ou responsável por sua morte.

As memórias de Violeta são talhadas por angústias. Surpreendentemente vemos emergir das entrelinhas de Os meus sentimentos a denúncia dos jogos de aparências que permeiam os relacionamentos humanos, das futilidades cotidianas, da superficialidade dos sentimentos. As memórias de Violeta são voláteis. Inesperadamente, transitam pelo perigoso terreno das incertezas, em que precisão e estabilidade soam como um clichê, discurso vazio ou lengalenga. Vemos, assim, assuntos tão ligados a nossa contemporaneidade perscrutarem as páginas desse livro. Consoante nos lembra Said, “o exílio é uma fratura incurável entre um ser humano e um lugar natal, entre o eu e seu verdadeiro lar: sua tristeza essencial jamais pode ser superada" (Said, 2003: 46). Para Violeta não houve cura para as tristezas que moveram cada um dia de seus dias até o momento do acidente. Ao adentrar a autoestrada na noite de chuva, a protagonista, a heroína de Dulce Maria Cardoso, sabia que empreendia uma última viagem: "rolo sobre as trevas" (Cardoso, 2005: 11); e que tal empresa terminaria com a elucidação da última lembrança "rolo pela luz" (Cardoso, 2005: 303).

nenhuma manhã me vai roubar este sonho tão bonito, nunca mais nenhuma manhã, a minha vida um sobressalto no sono continuado do universo, fecho os olhos por um bocadinho, um sono tranquilo, aqui dentro, aqui onde estou, aconteça o que acontecer nada acontece inesperadamente (Cardoso, 2005: 307).

$\mathrm{Na}$ fronteira da vida e da morte, Violeta acreditou que a libertação das frustrações que marcaram a sua trajetória deveria existir num outro plano, numa outra vida, onde poderia flanar levemente, desligada de todo o peso (inclusive corporal) que fora a sua vida terrestre. As memórias traçadas em Os meus sentimentos são contrárias em si mesmas, reversas - memórias que se iniciaram em trevas, mas que se fecharam iluminadas. Podemos considerar, portanto, que a rememoração/viagem de Violeta pode ser entendida em dois contrapontos. Se de um lado, ela lhe rendeu uma experiência sediciosa; por outro, não seria demais forçoso se tentássemos encontrar em meio à história de Violeta algum subsídio que nos desse alguma sensação de conforto. Assim, em meio à tão traumática experiência de mal estar em face de uma identidade fora dos padrões, as rememorações dessa heroína às avessas, também lhe trouxeram, ao menos, a possibilidade de enfrentar seus fantasmas e medos, funcionando como um bálsamo acalentador. De qualquer forma, após a leitura do texto, e de conhecermos as cicatrizes de uma mulher frustrada pelo desamor, ficamos com a sensação de que a matéria principal a ser tratada é a vida; e, para além dela, só nos resta o inesperado com que é tecido os nossos dias "os meus sentimentos".

Recibido: $13 / 10 / 2013$

Aceptado: 22/04/2014

\section{Referências bibliográficas}

Bakhtin, Mikhail (1988), Questões de literatura e de estética: a teoria do romance, trad. Aurora F. Bernardini et al., São Paulo: Hucitec.

Bauman, Zygmunt (2001), Modernidade líquida, São Paulo: Jorge Zahar.

Bosi, Ecléa (2009), Memória e sociedade. Lembrança dos velhos, 15 ed. São Paulo: Companhia das Letras.

Cardoso, Dulce Maria (2005), Os meus sentimentos, Asa: Alfragide.

Eagleton, Terry (1998), As ilusões do pós-modernismo, Zahar: Rio de Janeiro. 
Lourenço, Eduardo (1984), "Da ficção do império ao império da ficção", $D i$ ário de Notícias, Suplemento 10 anos de democracia, 24 de abril, pp. 26-27.

---- (1999), Mitologia da saudade: seguido de Portugal como destino, São Paulo: Companhia das Letras.

Paiva, José Rodrigues de (2010), "Revolução, renovação: Caminhos do romance português no século XX", en Elizabeth Dias Martins, Roberto Pontes, Patrícia Elainny Lima Barros, orgs., Falas \& textos: Escritos de literatura portuguesa, Fortaleza: Universidade Federal do Ceará.

Ribeiro, Margarida Calafate (2012), "O fim da história de regressos e o retorno a África: leituras da literatura contemporânea portuguesa”, em Itinerâncias - percursos e representações da pós-colonialidade. Disponível em: http:// www.ces.uc.pt/myces/UserFiles/livros/1097_MCR_fim_hist_reg_Itinerancias.pdf (consulta: 3-06-2014)

Said, Edward (2003), Reflexões sobre o exílio e outros ensaios, Trad. Pedro Maia Soares, São Paulo: Companhia das Letras.

Searle, John R. (1979), Expression and meaning, Cambridge: Cambridge University Press. 